\title{
South African Journal of Business Management: Annual editorial overview 2019
}

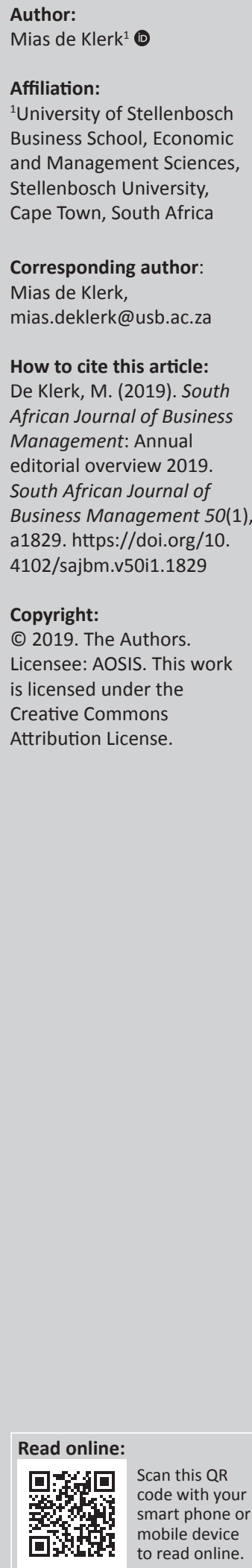

\section{Introduction}

It is with great pride that I welcome you to the 2019 volume of the South African Journal of Business Management (SAJBM). This particular volume of the SAJBM celebrates a half-century of publishing articles that have real significance for management theory and practice. The last two years have been a time of many transformative changes for the SAJBM. Taking over the role as the editor-inchief of the SAJBM from Prof. Eon Smit in 2018 was a great honour and an even greater responsibility. More than a year has passed since moving to AOSIS as publisher and moving from a printed journal early in 2018 to a journal that is exclusively published as an online journal. Another milestone development was the successful launch of the first open access edition of the SAJBM in the middle of 2018. Notwithstanding these huge interventions and significant milestones, the great support from the AOSIS staff made this transition easy and almost painless and now, in 2019, we can taste some of the success of these decisions. With a newly appointed Editorial Advisory Board and the amazing support that I receive from the managing editor and the AOSIS staff, I am full of confidence that we will continue on the commendable path on which Prof. Smit has put the SAJBM.

\section{Ensuring journal quality}

Since the SAJBM's inception 50 years ago in 1969, the journal continues to be recognised internationally as a leading-edge accredited journal for publishing quality research in the field of business science.

The SAJBM provides cutting-edge, peer-reviewed research in all fields related to the vast complement of business science. The metrics and accreditation listings of the SAJBM, including ISI/Web of Science, Chartered Association of Business Schools, Scopus, Australian Business Deans Council, EBSCOHost, Directory of Open Access Journals, Norwegian Register for Scientific Journals and Scimago, confirm the international recognition of the journal. It also confirms the rigour of our double blind-peer review processes in ensuring the publication of high-quality scientific material with impact and practical application.

However, this quality comes at a price for the authors who submit manuscripts for publication. A total of 671 submissions were received between 2018 and October 2019. Unfortunately, 73\% of the manuscripts were desk rejected during this period. In other words, the manuscripts were declined by the editor, without sending it for peer review. Of the manuscripts that were sent for external review, another $40 \%$ were rejected.

These rejection rates are quite high and may appear to be very harsh, especially the desk rejections. Being an author myself, I am truly aware of the disappointment and emotional turmoil one goes through when one's manuscript is declined, especially when this is done without peer review. However, there are good reasons to be frugal when considering new submissions. Firstly, we have to honour the effort of our team of reviewers who selflessly dedicate their time to do the reviews as a free service to the scientific community.

The editor has to ensure that the reviewers' time is not absorbed unnecessarily by manuscripts that from the beginning are unlikely to obtain a favourable review. Furthermore, in order to keep our international rankings and standings, we have no choice but to only accept the very best of the submissions for publication.

To avoid desk rejection, my best advice to prospective authors is to study the submission guidelines carefully, ensuring that an excellent editing is done, clarity of writing throughout an article is maintained, literature study conducted is scientifically sound and comprehensive, and rigour is applied in the scientific method and its description. 


\section{International footprint}

It is particularly encouraging that the SAJBM is increasingly developing into a truly international journal that caters not only to the needs of South Africa or the African continent, but also to the needs of the international scientific community. Indeed, the international footprint of the SAJBM is now bigger than the South African footprint. The proportion of peer-reviewed papers published in the SAJBM, which had at least one author with a non-South African address, has grown from $38 \%$ in 2016 to $58 \%$ in 2018 - almost $60 \%$ of the authors are now internationally based. Moreover, interest in the SAJBM is primarily from the international community, with $55 \%$ of the visitors to the SAJBM's website from Asia, $26 \%$ from Africa, $11 \%$ from Europe and $7 \%$ from the Americas. According to Google Analytics, the SAJBM is read in 144 countries worldwide, including 35 African countries.

The statistics noted above confirm the expanding international footprint of the SAJBM. Clearly, the 'South African' notation in the name of the SAJBM now only refers to the country where the journal is housed, and cannot and should not be understood as a journal that is only focused on Southern Africa. It is with this background that we are increasingly looking for submissions that have international application and that are likely to be of interest to the wider and global reading audience of the SAJBM. Submissions that are overly focused on what is happening within too narrow a geographical context, at the cost of losing focus on the more general scientific problem, are viewed with much caution in the editorial review process.

\section{Our review process}

We understand that all authors would like to get feedback on their submissions as soon as possible and expect a limited period until publication if the manuscript was accepted. In 2018, the time between receipt of a manuscript and its publication (of successful articles) was 114 days and in 2019 it was 98 days. This is a great improvement from the period before 2018. We do not have accurate information about the period before 2018, but the time to publication was markedly longer before we moved from being a printed journal to an online journal in 2018. Nevertheless, we are not satisfied with this performance and continually strive to reduce the time from submission to publication. The most critical challenge is probably to find suitably qualified and willing referees, as the volume of papers submitted tends to increase from year to year. The availability of competent reviewers has a notable impact on the turnaround time of submissions to the SAJBM.

Although the official statistics show that we use around 42 reviewers annually, we have to contact and work with many more potential reviewers in order to obtain two reviewers who would be willing to do the review.

For example, in the case of one article, we had to contact 11 reviewers before we could find two willing and capable reviewers. And of course, life happens to all of us and some reviewers may no longer be available for the second or third rounds of review so that new reviewers have to be obtained.

In order to relieve the burden of reviewers, to ensure we have a reviewer corps for the wide variety of fields that the SAJBM covers and to reduce the time from submission to publication, we have registered 840 new reviewers since the middle of 2018. Without the double blind-peer review process, we will not be able to maintain our international accreditations. New contributors of papers to the journal have proven to be a trustworthy source of new referees in certain subject areas where critical shortages are developing. I would, therefore, like to encourage our authors and readers to make themselves available for a review if approached for this task. As scientists and authors, we are all dependent on getting our work published and therefore to be reviewed by other scientists. It is, therefore, every scholar's duty to return this favour and act as a peer reviewer for others.

\section{Ethical publication}

Publication ethics forms an integral part of the pre-screening and peer-review processes. AOSIS is a member of the CrossChecks plagiarism detection initiative and endorses and applies the standards of the Committee on Publication Ethics (COPE) which promotes integrity in peer-reviewed research publications. The SAJBM is also a member of COPE and the editors use iThenticate software for checking the originality of submissions received. Submissions that do not conform to acceptable originality standards will not be considered for peer review. Indeed, with the assistance of AOSIS, all submissions are since late 2018 automatically assessed for similarity with published material through iThenticate. The iThenticate report of every submission is scrutinised and, unfortunately, we have had to reject several submissions because of unacceptably high similarity with already published material. Information on the peer-review and ethics practices applied by the SAJBM publication process is available on the journal's website.

\section{Overview of article topics: South African Journal of Business Management, volume 50 (2019)}

It remains an explicit aim of the SAJBM to promote and publish research with impact. The range of articles published in the 50th volume of the SAJBM does not only demonstrate the international nature of the journal as explicated earlier, but also its coverage of the broad field of business science. The articles explore a large variety of interesting topics from quite diverse fields, which are relevant to the world of business today. For instance, the articles range from leadership to marketing, governance to coaching, entrepreneurship to tax and finance, economics to organisational behaviour, and operations to innovation and technology.

The SAJBM provides the opportunity to present your research and contribute to the growing body of scientific knowledge 
about the science and art of business management. I trust that you will find the articles in this volume to be insightful and useful as with previous volumes. In our continued striving to improve our offering to you, we really would appreciate any feedback that you may have.

\section{Conclusion}

The successful annual publication of the SAJBM volume is not because of the editor-in-chief. Rather, it is a collaborative team effort. I would like to express my gratitude to the scholarly and scientist-practitioner community who make use of our articles, either in practice or by incorporating them into their scholarly endeavours. I would also like to extend a heartfelt 'thank you' to all authors for their respective contributions to ensure the SAJBM remains representative of the developments in business and management science. But the biggest 'thank you' must go to the reputable and committed team of scholarly peer reviewers.
Our reviewers selflessly give their time and energy to review the submissions and to ensure the publication of high-quality articles, and they do so without reward and often after hours. Thank you so much, you are stars and the cornerstone of the success of the SAJBM. Last, but not least, I would like to thank Dr Lara Skelly, the managing editor, and the commitment and support from an amazingly accomplished AOSIS staff. A huge word of thanks to everyone for your cooperation and hard work to ensure the success of SAJBM management and administration.

I am excited about the future of SAJBM and believe that the significant collaboration efforts we annually experience with our community of scientists, practitioners and supporting staff will help to further advance the field of business and management science to the benefit of individuals, organisations and society as a whole. 